\title{
Campeonato escolar e deficiência visual: o discurso dos professores de educação física
}

\author{
Afonsa Janaína Silva* \\ Edison Duarte** \\ Jose Julio Gavião Almeida***
}

\begin{abstract}
Resumo: A Educação Física representa um importante meio para o desenvolvimento global do aluno com deficiência, por proporcionar o reconhecimento dos limites e possibilidades do "corpo" junto ao convívio social. Objetivou-se neste estudo analisar as concepções dos professores de educação física sobre a participação de alunos com deficiência visual em práticas relacionadas à educação física. Os professores apesar de conscientes do processo de inclusão possuem dúvidas sobre suas implicações e articulação de seus conhecimentos para atuar. Uma Educação Física de qualidade necessita verificar e potencializar o conhecimento que permeia os professores, constituindo assim uma atuação adequada a todos os alunos.
\end{abstract}

Palavras-Chave: Educação Física. Portadores de deficiência visual. Esportes.

\section{INTRODUÇÃo}

O termo inclusão na educação comum surge oficialmente no cenário internacional após a Declaração de Salamanca registrada pela UNESCO em 1994 (UNESCO, 1994).

No Brasil, os preceitos constitucionais determinam que o direito à educação dos alunos com necessidades especiais deverá ser garantido, e a Leis de Diretrizes e Bases da Educação Nacional

\footnotetext{
*Universidade São Francisco de Bragança Paulista e Faculdades Integradas Einstein de Limeira. Limeira, SP, Brasil. E-mail: afonsa_silva@yahoo.com.br

${ }^{* *}$ Faculdade de Educaçao Física. Universidade Estadual de Campinas. Campinas, SP, Brasil. E-mail: edison@fef.unicamp.br

***Faculdade de Educaçao Física. Universidade Estadual de Campinas. Campinas, SP, Brasil. E-mail: gaviao@fef.unicamp.br
} 
(LDB) 9.394/96 garante a inclusão dos alunos com necessidades especiais no ensino regular e em todas as atividades de seu contexto (SENADO FEDERAL, 2010; CÂMARA DOS DEPUTADOS, 2010).

Tendo em vista esse novo cenário da educação brasileira, com a participação efetiva de pessoas com deficiência no contexto escolar, buscamos repensar a educação física escolar de forma a promover a participação desses em todas as práticas que a envolve.

Segundo Sherrill (1981), a escola ${ }^{1}$ ou instituto especializado é o principal meio de aprendizagem da pessoa com deficiência visual DV, tendo como principais agentes os professores e as práticas sistematizadas - o que torna a escola um elemento de importância crucial ao desenvolvimento das crianças.

O convívio familiar pode ser decisivo e primordial para a aprendizagem da pessoa com deficiência visual. No entanto, o tempo disponível e muitas vezes o preparo especializado dos familiares é muito pequeno, e assim este espaço fica diminuído e insuficiente, se comparado com o ambiente escolar para formação das pessoas com deficiência visual.

No Brasil, a educação voltada às pessoas com deficiência é promovida em escolas especializadas, bem como em instituições especiais voltadas muitas vezes ao atendimento específico de uma deficiência. A partir da LDB 9.394/96, este atendimento passou a vigorar também nas escolas públicas e regulares (CÂMARA DOS DEPUTADOS, 2010).

Dentre as práticas sistematizadas apresentadas na escola, podese ressaltar as desenvolvidas nas aulas de educação física, as quais permitem um reconhecimento do próprio corpo por parte do aluno, assim como um amplo convívio social, sendo um veículo importante para o desenvolvimento motor e social da pessoa com DV.

${ }^{1} A$ autora reporta-se neste texto a escola pública ou residencial, como opções nos Estados Unidos 
As práticas esportivas podem promover o desenvolvimento das habilidades motoras do aluno com D.V., como também a orientação e mobilidade dos mesmos, porém os alunos que apresentam deficiência visual são muitas vezes pouco estimulados nas escolas ${ }^{2}$ (PONCHILLIA; STRAUSE; PONCHILLIA, 2002).

Pesquisas demonstram que a pessoa com DV apresenta um déficit no desenvolvimento motor em comparação ao de uma pessoa sem tal deficiência (FAZZI et al, 2002; DEPAUW, 1981). Tal desvantagem pode ser em decorrência de complicações secundárias à deficiência, caracterizadas pela influência do ambiente, como oportunidades, cultura, e não pela perda ou anormalidade da função visual propriamente dita (OLIVEIRA FILHO, ALMEIDA, 2005; MÜNSTER; ALMEIDA, 2005; HOPKINS et al, 1987). Para Craft (1990) a perda visual não é a causa direta de nenhuma característica motora ou física.

Criar oportunidades para que a pessoa com D.V. movimentese explorando o meio ambiente de forma segura é importante para minimizar os possíveis atrasos em seu desenvolvimento. Programas de Educação Física com o objetivo de ensinar estes alunos independência e auto-suficiência poderão incrementar o desenvolvimento global dos mesmos (CRAFT, 1990; KOBBERLING; JANKOWSKI; LEGER, 1991).

Estudos demonstram que pessoas com D.V. que tiveram suas primeiras experiências em práticas esportivas durante os anos escolares têm maior propensão a manterem-se engajadas na prática durante a vida adulta, podendo engajar-se até mesmo em programas de alto rendimento esportivo (SHERRILL; POPE; ARNHOLD, 1986; PONCHILLIA; STRAUSE; PONCHILLIA, 2002).

Segundo Münster e Almeida (2006) a diversidade está presente no programa de atividade motora voltado à inclusão, em diferentes aspectos: nas metas, nos currículos, nos conteúdos, nas estratégias e procedimentos pedagógicos, nos materiais e recursos empregados,

${ }^{2}$ Os autores reportam-se neste estudo a escola regular e pública dos Estados Unidos.

Movimento, Porto Alegre, v. 17, n. 02, p. 37-55, abr/jun de 2011. 
nos locais e ambientes de intervenção, nos métodos de avaliação e em todos que participam do processo.

Desta forma a ênfase do trabalho recai sobre o programa e não sobre a deficiência. Num programa criado neste sentido, a compreensão da deficiência deve pautar-se pelo potencial do indivíduo e das pessoas que o rodeiam e não pela limitação, comprometimento ou falta de funcionalidade em um órgão ou segmento corporal (MÜNSTER; ALMEIDA, 2006).

Neste sentido, este estudo propõe-se a analisar as concepções dos professores de educação física atuantes na rede regular e pública de ensino sobre a participação de alunos com deficiência visual em práticas relacionadas à educação física escolar, buscando compreender como estes enxergam o aluno com deficiência e seu envolvimento nas aulas de educação física.

\section{Procedimentos Metodológicos}

Foram sujeitos deste estudo professores de educação física escolar integrantes do quadro de professores das escolas estaduais do interior do estado de São Paulo, e participantes da Olimpíada Colegial do Estado de São Paulo com equipes nas modalidades Futsal, Atletismo e Xadrez, por essas já apresentarem adaptações à prática esportiva da pessoa com deficiência visual, como também professores que participam na organização dos referidos jogos. Participaram da pesquisa nove professores de Educação Física, com média de doze anos de atuação em campeonatos escolares, sendo seis professores da rede estadual de ensino de escolas a cargo de uma mesma diretoria de ensino e três responsáveis pela organização da Olimpíada Estadual de São Paulo em suas diferentes etapas. Este número restrito de professores foi determinado pela escolha de professores de uma mesma diretoria de ensino e que atuassem nos campeonatos escolares. A participação foi voluntária, sendo o sigilo de informações assegurado através do termo de consentimento livre e esclarecido. 
O presente estudo foi submetido a aprovação do comitê de ética de São Paulo tendo sua aprovação em 31/07/07, parecer do projeto no705/2006

Os locais de coleta de dados foram escolas estaduais do interior do estado de São Paulo, as quais foram determinadas pela escolha da diretoria de ensino e o cruzamento com os dados das escolas que já haviam participado da Olimpíada nas modalidades atletismo; também foram locais de coleta de dados a diretoria de ensino do interior do estado de São Paulo, onde se concentrava o maior número de escolas com equipes nas três modalidades referidas, e as Secretarias da Educação e de Esporte, Lazer e Turismo, responsáveis pela organização do campeonato nesta região.

\subsection{ENTREVISTA}

Para coleta dos dados foi realizada uma entrevista pessoal semiestruturada. A entrevista semi-estruturada permite ao entrevistado esclarecer os pontos colocados, segundo seus conhecimentos sobre o assunto tratado (LAKATOS; MARCONI, 1985).

Para o presente trabalho foram destacadas as questões que direta ou indiretamente resultaram do questionamento sobre a inclusão de alunos com deficiência visual nas práticas da educação física escolar.

O roteiro de entrevista era composto por três blocos de perguntas, I - sobre a pedagogia do esporte escolar, II sobre a pratica esportiva da pessoa com DV e III - sobre o processo de inclusão, com nove questões no total. As entrevistas levaram de 30 a 40 minutos para serem realizadas, os professores respondiam as perguntas sem interferência do entrevistador. Os blocos utilizados para este trabalho foram II e III. 


\subsection{MÉTOdo de AnÁLISE}

Os dados levantados foram analisados através do método de análise de conteúdo proposto por Bardin (2002). Esta técnica de investigação permite a leitura e interpretação de conteúdos de ilimitadas classes de conhecimentos, partindo de uma descrição objetiva e sistemática dos conteúdos, manifesto das comunicações (MYNAYO, 1993).

Dentre as diferentes técnicas de análise de conteúdo, elegemos a análise de enunciação para tratarmos os discursos de nossos sujeitos. A análise de enunciação considera o discurso não como um dado, um produto acabado, mas como um processo de elaboração com todas as contradições, incoerências e interpretações que isso comporta. Um processo onde são produzidos sentidos e transformações (BARDIN, 2002). A análise que seguidamente se apresenta apoiou-se num conjunto de critérios associados a fases tal como foram descritos por Bardin (2002).

\section{Resultados}

A análise das entrevistas permitiu identificar três importantes aspectos do pensamento dos professores a respeito da inclusão de alunos com deficiência visual em práticas relacionadas à educação física escolar: capacitação, estrutura e o aluno com deficiência.

As perguntas analisadas referem-se ao modo como os professores enxergam as implicações que o campeonato escolar traz à pessoa com DV e sobre a possibilidade de participação destes nos atuais campeonatos da rede de ensino.

Os discursos aludem mais às queixas surgidas após a institucionalização da inclusão do que à relação de conhecimentos e conteúdos que os professores de Educação Física dominam e podem articular para atender a todos seus alunos. Há uma clara dificuldade entre os entrevistados em relacionar seus conhecimentos teóricos e a experiência com outros públicos ao trabalho inclusivo. 


\subsection{CapacitaÇÃo}

$\mathrm{O}$ aspecto capacitação trata do preparo profissional para atender o aluno com DV, seja na formação inicial ou continuada do professor. Os discursos aludem à falta de capacitação profissional para atender as necessidades deste público, sendo as contribuições ofertadas aos alunos e a real participação destes comprometidas diretamente por este aspecto.

Sujeito I - (Olha eu vejo assim, o professor a nível de Estado a gente não tem um preparo tá, adequado para trabalhar por exemplo com o deficiente visual ou um cadeirante tá, mas a gente né, uma pessoa, um professor, um mestre que nos dê essa possibilidade de um treinamento que eu acho que a inclusão dessas pessoas, desses alunos dentro da escola do estado é muito importante).

Sujeito II - (Então acho muito importante estar fazendo um trabalho diferenciado pra eles, porque eles são pessoas diferenciadas e eu acho que eles merecem tanto quanto os outros e não tem. Aí a escola hoje obriga a receber esses alunos, mas não tem um tratamento diferenciado, o professor não consegue fazer o tratamento diferenciado pra ele tanto pela capacidade do professor mesmo por ele não ter disciplinas específicas para isso [...]).

Sujeito VII - (Nada impede que também a participação dos deficientes visuais com uma coordenação, com uma coordenação também paralela que é o pessoal especializado nesta clientela [...]).

A primeira preocupação que surge é a formação especializada para o atendimento à pessoa com deficiência, em detrimento de todo o conhecimento específico à área de Educação Física que é a base para o trabalho com os diferentes públicos abrangidos pela área, seja na escola, clube, praça de esportes, etc.

Esta constatação denota uma lacuna na articulação entre conhecimentos teóricos e práticos, principalmente quando esta preocupação surge no discurso sobre as contribuições que o processo que envolve um campeonato pode trazer aos seus diferentes participantes, porém denotam também a importância de experiências práticas com diferentes públicos durante a formação profissional. 


\subsection{ESTRUTURA}

Foram levantados problemas tanto de natureza física quanto organizacional, os quais no discurso dos sujeitos influenciam diretamente a inclusão de alunos com DV nos campeonatos escolares.

Sujeito III - (Se forem em grupos de deficientes separados dos normais eu acho que daria para participar, agora junto... aí é difícil. Ah, porque [...] Bom, apesar que, eu trabalho na Prefeitura também, em duas escolas e lá a gente tem um campeonato e tem alunos deficientes físicos participando, deu certo. Agora visuais, eu já tive alunos com problemas visuais foi difícil na aula de Educação Física eu ter que adaptar as coisas para ela fazer, uma bola com guizo, essas coisas que você tem que ver na escola).

Sujeito VII - (Como eu te falei. É [...] hoje, a participação de deficiente visual na Olimpíada eqüitativamente é inviável. Eqüitativamente, senão pode colocar o individuo deficiente visual dentro do regulamento, das exigências regulamentares, das regras das confederações e não é o que realmente essa clientela seja possível desenvolver qualquer participação eqüitativamente, nada impede que se faça uma comissão digna, quando eu falo digna, eu falo de pessoas especializadas nessa clientela e se faça uma proposta a nível da secretaria da educação através da secretaria da educação, para mim este é o meio, nada impede que se estenda a secretaria de esporte, lazer e turismo, porque as duas tem parceria e incluída na resolução conjunta, mas que tenha uma atividade paralela [...]).

Sujeito VIII - (Eles poderiam trazer a contribuição desde que fossem adaptados nos moldes que se encontram hoje sem nenhuma adaptação acho que o que traria seria mais prejuízo do que benefícios para os deficientes, né, porque eles precisam de alguma adaptação para eles participarem, enquanto que o que acontece eles estão adaptados somente para as pessoas que podem ver alguma coisa).

A adaptação nos discursos é vista como algo que surge somente para que se atenda a pessoa com deficiência sem considerar a nova realidade que a escola inclusiva denota. As adaptações são sugeridas 
de formas específicas às deficiências e não buscando contemplar um novo meio que se configura através da participação do aluno com deficiência visual.

A participação e as contribuições da prática são vistas sobre o prisma de um trabalho específico à pessoa com deficiência, remetendo-se a ações integrativas e não inclusivas.

Foi apontada também a baixa demanda, porém deve-se lembrar que o número de alunos com deficiência visual matriculados em classes comuns da rede pública de ensino, segundo dados do MEC, vêm crescendo. O problema hoje é saber em quais escolas/ níveis de ensino estes alunos se encontram.

\subsection{O ALUNO COM DEFICIÊNCIA}

A marca fundamental deste aspecto parece revelar uma forma de enxergar a pessoa com deficiência ainda perante um ideário pautado no modelo médico de deficiência, preconizando as limitações e a integração destes indivíduos.

Sujeito I - (Sim, primeiramente o aluno deficiente é uma pessoa comum, tá, ele é uma pessoa normal, claro que tem seus problemas limitados, mas ele pode tranqüilamente participar do campeonato colegial, tá. [...] então, isso, isso quer dizer que você consegue realmente fazer dos alunos com deficiência a ser um aluno normal, uma criança, um adolescente normal dentro dos colegas, tá).

Sujeito VIII - (A participação seria muito interessante e muito boa para os alunos que não tem nenhuma deficiência e também importantes para os portadores de deficiência, mas pela falta de adaptação e como é uma competição e que eles buscam a vitória então eles não vão relevar a deficiência desse portador e ele pode até se machucar, seria importante a participação, mas como são as de pessoas tidas normais acho que seriam prejudicados nessa parte, porque eles teriam uma deficiência enquanto os outros não teriam e eles iriam passar por cima dessa deficiência para buscar a vitória).

As declarações apresentam preocupações voltadas à adaptação dos alunos com deficiência ao meio e ao modo como a presença 
destes afetará este meio. Desta forma, os olhares voltam-se às limitações que os alunos com deficiência apresentam ao se relacionar com o meio e não às potencialidades deste aluno e às possibilidades de acomodação do meio e dos envolvidos nele à nova situação.

Diante deste aspecto ressalta-se ainda um único discurso que denota a padronização imposta pelo ensino tradicional, no qual as diferenças são ignoradas em prol da enganosa maioria.

Sujeito II - ([...] pela quantidade de alunos que tem dentro da sala de aula não tem como você fazer um trabalho só pra aquele, só pra dois ou três alunos aí você excluí o resto da sala e a gente tem que trabalhar sempre com a maioria com mais e você tenta levar sempre a maioria da sala e você deixa uns pra trás até mesmo os bons demais ficam um pouco pra trás porque você não consegue avançar com eles, então você tem que segurar um pouco para quem está lá trás, então tudo o que a gente faz tem, a gente tem que tentar fazer o melhor para estar trazendo essas pessoas [...]).

De forma geral, os sujeitos admitem que os campeonatos escolares podem trazer contribuições ao aluno com deficiência visual, porém não esclarecem quais seriam estas, bem como, deixam transparecer dúvidas quanto ao seu papel e desempenho diante da inclusão destes alunos.

Quanto à participação, o discurso está pautado nas limitações do ambiente e dos profissionais envolvidos. As respostas denotam resquícios do ideal de integração, no qual os alunos com deficiência habitam o mesmo ambiente, mas não participam das mesmas atividades.

\section{Discussão}

Os dados demonstram que apesar dos esforços da Secretaria de Educação Especial em proporcionar ações de formação continuada para atuação na escola inclusiva aos professores de educação física escolar, e ao fato de que muitas escolas de educação superior já oferecerem em seus currículos disciplinas que contemplem 
a educação física adaptada, são muitas as dúvidas dos professores de educação física ao se depararem com classes inclusivas.

A Educação Física vem, ao longo destas últimas décadas no Brasil, desconstruindo antigos ideários em prol da construção de uma área de conhecimento voltada às necessidades globais dos indivíduos e de sua interação em sociedade. Fazem parte deste processo as novas teorias da educação física escolar e também os conhecimentos produzidos em busca do atendimento às pessoas com deficiência.

Todas as teorias desenvolvidas neste período, de diferentes formas, trabalham com os mesmos conhecimentos, ou seja, aqueles historicamente gerados pela área, porém de diferentes formas buscando não mais atender aos sistemas de governo, mas sim aos interesses dos alunos.

O currículo inclusivo não se diferencia em conteúdos; os mesmos conhecimentos historicamente gerados podem e devem ser trabalhados, mas compreendendo técnicas, formas de organização e adaptações específicas (MÜNSTER; ALMEIDA, 2006).

Num programa voltado à inclusão, é necessário investir na metodologia e nas estratégias de ensino-aprendizagem, conferindo um tratamento pedagógico adequado às atividades ministradas e onde se contemplem as necessidades do grupo com quem se trabalha (MÜNSTER; ALMEIDA, 2006).

Ao elaborar um programa de atividades para atender em um mesmo ambiente pessoas com e sem deficiências, o professor deve examinar e investigar as circunstâncias relativas aos indivíduos que compõem seu grupo. É imprescindível conhecer as preferências e experiências anteriores de ambas as partes, buscando metas e interesses em comum (MÜNSTER; ALMEIDA, 2006).

Desta forma, o professor deverá abandonar os valores da escola tradicional. O indivíduo será visto em suas potencialidades e não mais como algo abstrato, o foco da educação estará no processo e não no produto a ser alcançado, a proposta pedagógica volta-se à 
diversidade encontrada no grupo e não à uniformização, e assim, o currículo estará sempre em construção e não já construído (RODRIGUES, 2001).

Neste contexto é evidente a necessidade de criação de novos conhecimentos emergentes do novo contingente social encontrado nas escolas inclusivas, os quais devem ser dirigidos e adequados a nova configuração das classes inclusivas, considerando a diversidade cultural, social, etc. (CARMO, 2006).

Neste ponto, encontra-se outro aspecto levantado pelos dados do estudo. A adaptação foi o primeiro passo em busca da inserção das pessoas com deficiência em atividades motoras. A preocupação estava voltada em como levar a estas pessoas os conhecimentos historicamente construídos pela Educação Física, principalmente os esportes, a este grupo (CARMO, 2002).

$\mathrm{O}$ acesso às diferentes ordens de conhecimento é garantido por lei às pessoas com deficiência, e muitas vezes algumas atividades só são acessíveis a estes através de adaptações.

O processo de adaptação é contínuo, dinâmico e recíproco e consiste na articulação de variáveis em busca das metas desejadas (MÜNSTER; ALMEIDA, 2006).

As adaptações podem ser de diferentes ordens: nos equipamentos; nos sistemas de informação e comunicação; no ambiente físico e nas regras. Estas são utilizadas conforme a necessidade de cada grupo (MÜNSTER; ALMEIDA, 2006).

As adaptações foram e são necessárias à transmissão dos conhecimentos já consolidados. Estas também abriram espaços para a descoberta das potencialidades da pessoa com deficiência, o que pode estimular o desenvolvimento de novos conhecimentos que trabalhem com o potencial dos grupos formados na diversidade.

Este contexto permite que o professor explore a adaptação de variáveis para transmitir os conhecimentos já consolidados, mas também exige do mesmo que volte seu olhar às possibilidades do 
grupo que trabalha e busque desenvolver com o este grupo novas atividades que partam do conhecido e aflorem as potencialidades na diversidade.

O último aspecto destacado do discurso dos sujeitos trata do modo como estes enxergam o aluno com deficiência. A análise demonstra que o discurso destes professores ainda está pautado por ideais constituintes do movimento de integração.

Segundo Sassaki (1997) o modelo integrativo preconizava que a pessoa com deficiência seria integrada à sociedade, desde que fosse capaz de moldar-se aos requisitos dos serviços especiais; acompanhar procedimentos tradicionais; lidar com atitudes resultantes de estereótipos, preconceitos e estigmas; desempenhar papéis sociais individualmente com autonomia, mas não necessariamente com independência. E a sociedade em contrapartida não precisaria modificar-se em nada para recebê-los.

Nesta perspectiva, a inserção da pessoa com deficiência é baseada no princípio de normalização, o qual propõe que todo indivíduo tem direito de vivenciar um estilo de vida padrão ou comum a sua cultura, em detrimento de adequar seus serviços e atendimentos às necessidades das pessoas com deficiência. Desta forma, passouse a impor um padrão de vida, no qual a deficiência é entendida como um déficit a ser superado (MÜNSTER; ALMEIDA, 2006).

As práticas sociais inclusivistas preconizam um movimento bilateral, no qual as pessoas com deficiência e a sociedade visam uma meta comum.

A inclusão social constitui-se em um processo de preparo mútuo, no qual a sociedade se adapta para atender em seus sistemas sociais gerais pessoas com deficiências e simultaneamente as pessoas nestas condições se preparam para assumir seus papéis na sociedade (SASSAKI, 1997).

Os discursos analisados denotam a preocupação com ideais voltados à padronização de um estilo de vida e às atividades que 
contemplem uma maioria que talvez apresente características comuns, em detrimento de atividades que explorem a diversidade de potencialidades existentes em uma sala inclusiva.

As comunidades humanas em geral consideram "normal" o que é semelhante, conhecido e previsível, remetendo à margem da sociedade o que é diferente, desconhecido e imprevisível (RODRIGUES, 2001).

Todos os seres humanos são diferentes e desiguais, porque possuem naturezas biológicas diferentes e são socialmente desiguais (CARMO, 2002).

O reconhecimento por parte dos professores da diversidade que compõe classes formadas por alunos com e sem deficiência acaba por eliminar o conceito das classes homogêneas, nas quais todas as crianças deveriam ser "iguais", abrindo espaço para as potencialidades que afloram da diversidade e para a descoberta de importantes fatores ao progresso educacional.

\section{ConsideraÇões Finals}

Os resultados deste estudo demonstram que a realidade da escola hoje está longe de se encaixar nos ideais inclusivistas; o demonstrado é a transição entre os princípios de integração para os de inclusão. Esta transição acarreta inúmeras dúvidas aos professores, principalmente aqueles que concluíram sua formação antes mesmo destes ideais chegarem às universidades.

Ao voltar o olhar para o indivíduo e não para o produto criaramse novas demandas para educação, necessitando novas pedagogias, métodos, conhecimentos e conteúdos. E este estudo demonstrou a importância de investimento na formação básica e continuada dos professores de Educação Física (E.F.).

As discussões desenvolvidas para E.F. Escolar e para a E.F. voltadas às pessoas com deficiência, principalmente após a década de 80, contribuíram significativamente para a reestruturação da E.F., porém muitas vezes os professores que atuam na rede de ensino 
não tiveram acesso a estas discussões durante sua formação de base ou apresentam dificuldade de articulação entre os conhecimentos teóricos e suas práticas.

Nesta perspectiva, a formação profissional em Educação Física deve ser articulada de forma a aproximar os conteúdos teóricos à prática, levando o aluno ao exercício de articulação entre os conhecimentos teóricos e práticos para que ele possa buscar em suas experiências e conhecimentos ferramentas pedagógicas para atuar com qualidade em uma sociedade composta na diversidade.

Todo cidadão tem direito ao contato com os conhecimentos historicamente construídos pela Educação Física, como o esporte, as ginásticas, lutas, etc., podendo dispor de ferramentas pedagógicas diversas para isso, como a(s) adaptação (ões).

Independente do momento histórico em que um conhecimento é concebido e dos valores que são agregados a ele neste momento, este se torna patrimônio cultural, sendo parte do contexto social onde o ser humano circula. Mesmo não sendo praticado por um ou outro individuo, o conhecimento enquanto patrimônio cultural faz parte da história de qualquer um deles.

Em relação à pessoa/ criança com deficiência a Educação Física Adaptada fez e faz isso com grande destreza, porém é de extrema urgência que professores e pesquisadores comecem a olhar para as novas possibilidades dentro do contexto que o trabalho simultâneo com pessoas diferentes e desiguais gera para a criação de novas e diferentes estratégias pedagógicas.

Nesse sentido o desafio da inclusão não está simplesmente na capacitação "técnica" de professores para atuar com a pessoa/criança com deficiência, mas sim sobre a articulação dos conhecimentos desenvolvidos sobre todos os aspectos da Educação Física, tal como os produzidos pela Educação Física Adaptada ou as teorias pedagógicas idealizadas para Educação Física Escolar, para oferecer uma educação de qualidade a todos os alunos.

É preciso assegurar que, no processo de formação de recursos humanos, cujo principal veículo é a universidade, as questões 
relacionadas à nova demanda decorrentes da realidade imposta pela inclusão nas escolas sejam cada vez mais abordadas, de forma a aprimorar sua abordagem dentro da Educação Física, levando os profissionais da área a articular seus conhecimentos não para o atendimento isolado dos diferentes grupos, mas para atender com qualidade o grupo de diversidade formado na educação inclusiva. 
School championship and visual impairment: the discourse of physical education teachers.

Abstract: Physical Education is an important vehicle for the overall development of students with disabilities, since provides recognition of the limits and possibilities of the "body" in conjunction with the social life. The objective of this study was to analyze the concepts of Physical Education teachers about the participation of students with visual impairments in practices related to Physical Education. Although the teachers have conscience about of the inclusion process they have doubts about its implications and to articulate their knowledge to teach. A quality physical education is need to check, and empowering knowledge that permeates the teachers, thus providing an adequate performance for all students.

Keywords: Physical Education. Visually Impaired Persons. Sports.

Campeonato escolar y deficiencia visual: el discurso de los profesores de educación física Resumen: La Educación Física representa un importante medio para el desenvolvimiento global de los alumnos con deficiencia, por proporcionar el reconocimiento de los límites y posibilidades del "cuerpo" junto a la convivencia social. El objetivo de este estudio es analizar las concepciones de los profesores de educación física sobre la participación de alumnos con deficiencia visual en prácticas de la educación física. Los profesores a pesar de se concientes del proceso de inclusión tienen dudas sobre su implicancia y articulación de sus conocimientos al actuar. Una Educación Física de calidad necesita verificar y potencializar el conocimiento que poseen los profesores, proporcionando así un desempeño adecuado ante todos los alumnos.

Palabras clave: Educación física. Personas con daño visual. Deportes. 


\section{REFERÊNCIAS}

BARDIN, L. Análise de conteúdo. Lisboa: Edições 70, 2002.

CÂMARA DOS DEPUTADOS. Lei de Diretrizes e Bases da Educação Nacional. Lei no 9.394, de 20 de dezembro de 1996. 5 ed. Brasília: Biblioteca digital da Câmara dos Deputados, 2010. Disponível em: <www. portal.mec.gov.br/arquivos/pdf/ ldb.pdf>. Acesso em: 05 jan. 2011.

CARMO, A. A. Atividade motora adaptada e inclusão escolar: caminhos que não se cruzam. In:RODRIGUES, D. (Org). Atividade motora adaptada: a alegria do corpo. São Paulo: Artes Médicas, 2006. p 51-61.

CARMO, A. A. Inclusão escolar e a Educação Física: que movimentos são estes? Integração, Brasília, v. 14, ed.esp., p.06-13, 2002.

CRAFT, D. H. Sensory Impairments. In: WINNICK, J. P. (Org). Adapted physical education and sport. Illionois: Human Kinetics, 1990. p. 209-228.

DEPAUW, K. P. Physical education for visually impaired: a review of the literature. Journal of visual impairment \& blindness, New York, v.75, n. 4, p.162-163, apr. 1981 .

FAZZI, E. et al. Gross motor development and reach on sound as critical tools for development of blind child. Brain and development, Tokyo, v.24, n. 5. p.269-275, aug. 2002.

HOPKINS, W. G. et al. Physical fitness of blind and sighted children. European journal of applied physiology and occupational physiology, Berlin, v.56, n.1. p. 69-73, 1987.

KOBBERLING, G.; JANKOWSKI, L. W.; LEGER, L. The relationship between aerobic capacity and physical activity in blind and sighted adolescentes. Journal of visual impairment \& blindness, New York, v.85, n 9. p. 382-384, nov. 1991.

LAKATOS, E. M.; MARCONI, M. de A. Fundamentos de metodologia científica. São Paulo: Atlas, 1985.

MÜNSTER, M. A. van, ALMEIDA, J. J. G. de. Atividade física e deficiência visual. In: GORGATTI, M. G.; COSTA, R. F. da. (Org). Atividade física adaptada: qualidade de vida para pessoas com necessidades especiais. Barueri: Editora Manole, 2005. p.28-76.

MÜNSTER, M. A. van; ALMEIDA, J. J. G. Um olhar sobre a inclusão de pessoas com deficiência em programas de atividade motora: do espelho ao caleidoscópio. In: RODRIGUES, D. (Org). Atividade motora adaptada: a alegria do corpo. São Paulo: Artes Médicas, 2006. p 81-91.

MYNAYO, M.C. De S. O desafio do conhecimento: pesquisa qualitativa em saúde. 2 ed. São Paulo: Hucitec, 1993. 
OLIVEIRA FILHO, C. W.; ALMEIDA, J. J. G. de. Pedagogia do esporte: um enfoque para pessoas com deficiência visual. In: PAES, R. R.; BALBINO, H. F. (Org) Pedagogia do esporte: contextos e perspectivas. Campinas: Guanabara Koogan, 2005. p. $91-110$.

PONCHILLIA, P. E.; STRAUSE, B.; PONCHILLIA, S. V. Athletes with visual impairments: attributes and sports participation. Journal of visual impairment \& blindness, New York, v.96, n.4. p.267-272, apr. 2002.

RODRIGUES, D. A educação e a diferença. In: RODRIGUES, D. (Org). Educação e diferença: valores e práticas para uma educação inclusiva. Porto: Porto Editora, 2001. p.13-34.

SASSAKI, R. K. Inclusão: Construindo uma sociedade para todos. Rio de Janeiro: WVA, 1997.

SENADO FEDERAL. Constituição da República Federativa do Brasil (1988). Brasília: Secretaria Especial de Editoração e Publicações, 2010. Disponível em: <http://www.planalto.gov.br/ccivil_03/Constituicao/Constitui\%C3\%A7ao.htm>. Acesso em: 18 fev. 2011.

SHERRILL, C. Adapted physical education and recreation: a multidisciplinary approach. Dubuque: Wm C. Brown, 1981.

SHERRILL, C.; POPE, C.; ARNHOLD, R. Sport socialization of blind athletes: an exploratory study. Journal of visual impairment \& blindness, New York, v.80, n. 5, p.740-748, may 1986.

UNESCO. Procedimentos-Padrões das Nações Unidas para a Equalização de Oportunidades para Pessoas Portadoras de Deficiências, A/RES/48/ 96, Resolução das Nações Unidas adotada em Assembléia Geral. Salamanca: UNESCO, 1994. Disponível em: <www.portal.mec.gov.br/seesp/arquivos/pdf/ salamanca.pdf $>$. Acesso em: 18 fev. 2011.

Financiamento da pesquisa: CNPq

Endereço para correspondência

Afonsa Janaína Silva

Rua Pedro Vieira da Silva, 144 Apto D33

Jardim Santa Genebra - Campinas/SP

Cep 13080570

Recebido em: 05.03. 2011

Aprovado em: 15.07.2011 
